\title{
Congenital diaphragmatic hernia in a patient with tetrasomy $9 p$
}

\author{
Tiago Henriques-Coelho ${ }^{a, b}$, Natália Oliva-Teles ${ }^{c}$, M. Luz Fonseca-Silvac, \\ Dick Tibboel $^{\mathrm{d}}$, Hercília Guimarães ${ }^{\mathrm{b}, \mathrm{e}}$, Jorge Correia-Pinto ${ }^{\mathrm{a}, \mathrm{f}, *}$
}

\author{
${ }^{a}$ Division of Pediatric Surgery, Hospital de S. João, 4202-451 Porto, Portugal \\ ${ }^{\mathrm{b}}$ Physiology Department, Faculty of Medicine, University of Porto, 4200-319 Porto, Portugal \\ ${ }^{\mathrm{c}}$ Medical Genetics Institute, 4099-028 Porto, Portugal \\ ${ }^{\mathrm{d}}$ Erasmus Medical Centre, 3000 CB, Rotterdam, The Netherlands \\ ${ }^{\mathrm{e}}$ Neonatal Intensive Care Unit, Hospital de S. João, 4202-451 Porto, Portugal \\ ${ }^{\mathrm{f}}$ Life and Health Sciences Research Institute (ICVS), School of Health Sciences, University of Minho, 4710-057 Braga, Portugal
}

\section{Index words: \\ Tetrasomy 9p; \\ Isochromosome; \\ Congenital \\ diaphragmatic hernia}

\begin{abstract}
Tetrasomy of the short arm of chromosome 9 constitutes a rare condition resulting in a well clinically recognized syndrome. In our case, in addition to the characteristic phenotype at birth, the existence of a hernia-type Bochdalek diaphragmatic defect was found. Cytogenetic analysis revealed a nonmosaic case of an isochromosome of the entire short arm of chromosome 9 with no involvement of the heterochromatic region of the long arm: 47, XX, $+\mathrm{i}(9 \mathrm{p})$. Because chromosome 9 contains several gene locus for enzymes and receptors of the retinoid pathway, this case potentially contributes to retinoid hypothesis in the etiology of congenital diaphragmatic hernia.
\end{abstract}

(C) 2005 Elsevier Inc. All rights reserved.
In 1973, Ghymers et al [1] reported for the first time tetrasomy $9 \mathrm{p}$ as a rare chromosomal anomaly. Since that time, 44 cases are described either as mosaic or nonmosaic. Supernumerary isochromosomes derived from chromosome 9 may consist of the entire short arm, the entire short arm, and part of the heterochromatic region of the long arm or the entire short arm and part of the long arm extending to the euchromatic region. Tetrasomy of the short arm of chromosome 9 is now a clinically well-recognizable chromosomal syndrome [2]. The phenotype varies in severity

\footnotetext{
* Corresponding author. Escola de Ciências da Saúde, Universidade do Minho, Campus de Gualtar, 4709-057 Braga, Portugal.

E-mail address: jcp@ecsaude.uminho.pt (J. Correia-Pinto).
}

from neonatal death to mild developmental delay and minor anomalies.

Congenital diaphragmatic hernia (CDH) may occur as an isolated event, as part of a malformation syndrome, or associated with chromosomal defects [3]. CDH is most frequently documented with trisomy 18, 13, and 21 [4], although an association between $\mathrm{CDH}$ and chromosome $15 \mathrm{q}$ defects has also been documented [3,5]. Regarding chromosome 9 anomalies associated with $\mathrm{CDH}$, there are some anecdotal papers reporting deletions and translocations [5-7], but no case of tetrasomy has been reported.

Herein, we describe for the first time the presence of $\mathrm{CDH}$ in a newborn with multiple anomalies and tetrasomy $9 \mathrm{p}$ and combine it with a literature review of all previous reported cases with tetrasomy $9 \mathrm{p}$. 


\section{Clinical report}

A 43-year-old, gravida 5, para 3, O Rh+ white woman, apparently healthy, was admitted because of premature rupture of membranes at 31 weeks' gestation when hydrops fetalis was diagnosed. The woman had experienced a pregnancy loss twice because of spontaneous abortion, but the other 2 older children were healthy. The mother has no history of drugs, radiation exposure, or vitamin A supplementation. She had negative HBsAg and VDRL and had antibodies against rubeola virus but not to toxoplasmosis. She and her husband were unconsanguineous. There was no family history of congenital malformations. Prenatal sonography at 10, 17, and 24 weeks' gestation did not reveal any anomaly. A female newborn weighing $1810 \mathrm{~g}$, measuring $41 \mathrm{~cm}$ in length and $30 \mathrm{~cm}$ in head circumference, was delivered by cesarean section at 31 weeks. Apgar score was 2 and 8 at 1 and 5 minutes, respectively. Immediate resuscitation with endotracheal intubation and mechanical ventilation was initiated.

Physical examination of this neonate showed a multiple malformation syndrome with triangular facies, large anterior and posterior fontanels, hypertelorism, epicanthal folds, low-set and dysplastic ears, anteverted tip of the nose, short neck, brachycephaly, hypotonia, and an umbilical hernia. Echocardiography revealed a patent ductus arteriosus with a left-to-right shunt, a patent foramen ovale, and severe pulmonary hypertension. Cranial transfontanel sonography showed large ventricles and a grade I bilateral subarachnoid hemorrhage. Thoracic x-ray demonstrated a left diaphragmatic hernia. Surgical correction of diaphragmatic hernia was performed at the sixth day of age after stabilization and showed a typical Bochdalek diaphragmatic defect.

The child died after 37 days with sepsis. Necropsy revealed, in addition to a corrected left diaphragmatic hernia, a hypoplasic lung with bronchopulmonary dysplasia, intrahepatic biliary atresia with severe cholestasis, left ureteric duplication with fusion before the bladder entry, a pancreas with Langerhans hypertrophy and hyperplasia, depleted thymus with Hassall corpuscles, adrenal glands with pseudoacinar transformation, depleted lymph nodes, and kidneys with acute tubular necrosis.

\section{Cytogenetics and FISH studies}

Chromosome studies were performed in peripheral blood lymphocytes. According to standard cytogenetic procedures, GTG banding was used. The analysis revealed a supernumerary chromosome, suggesting an isochromosome (i) composed of 2 short arms of chromosome 9 [i(9p)].

\subsection{Complementary molecular cytogenetic studies}

Fluorescent in situ hybridization (FISH) using a whole chromosome painting probe specific for chromosome 9 (Cytocell, Cambridge, UK) confirmed that the

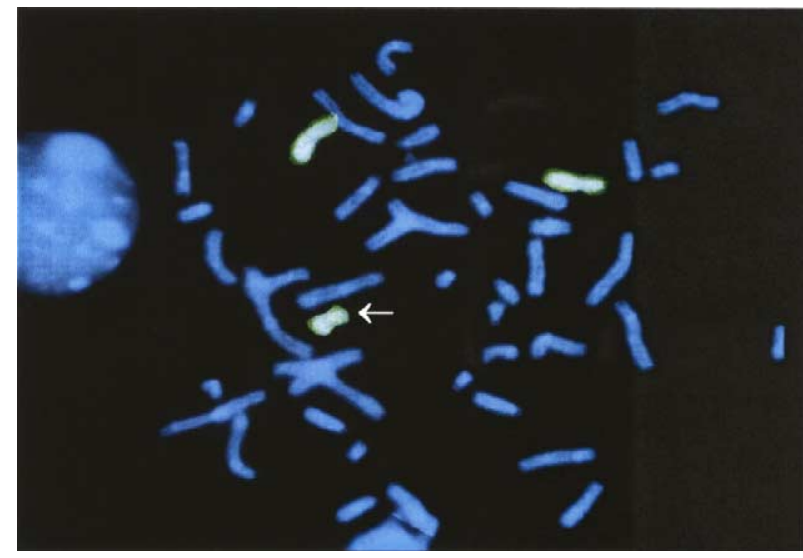

Fig. 1 FISH using a specific whole chromosome painting probe for chromosome 9 . The arrow shows the $i(9 p)$.

extra metacentric chromosome originated from a chromosome 9 and formed an isochromosome $9 \mathrm{p}$. Thus, the final karyotype was defined as $47, \mathrm{XX},+\mathrm{i}(9)$ $($ pter $\rightarrow$ p10 $::$ p10 $\rightarrow$ pter).ish $9(\mathrm{wcp}+)($ Fig. 1). The parental karyotypes were both normal.

\section{Discussion}

Autosomal tetrasomies are rare occurrences that result from supernumerary chromosomes involving mostly the short arms of chromosomes 9, 12, 18, and acrocentrics. Isochromosomes predominantly originate through maternal meiosis type II nondisjunction, followed by a rearrangement or centromeric misdivision, leading to duplication of the short arm and loss of the long arm [8]. Isochromosomes derived from chromosome 9 have been reported and may be grouped in 3 types: isochromosomes with a breakpoint at p10 with no portion of the long arm, isochromosomes with a small amount of the heterochromic region of $9 \mathrm{q}$ extending to $9 \mathrm{q} 12$ or $9 \mathrm{q} 13$, and isochromosomes with a large portion of the long arm of chromosome 9 extending to $9 \mathrm{q} 21$ or q22 [9]. Some patients with an extra isochromosome 9p have the abnormal cell line in all tissues investigated, but many display tissue mosaicism.

Tetrasomy of the short arm of chromosome 9 constitutes a clinically recognizable chromosomal syndrome first described by Ghymers et al [1]. Since then, a total of 44 cases have been reported in English literature. A number of cases were diagnosed prenatally, and the most common ultrasound findings are intrauterine growth restriction, ventriculomegaly, cleft lip/palate, and genitourinary or renal anomaly. As this pattern is suggestive of trisomy 13, chorionic villus sampling or amniocentesis is necessary to make the prenatal diagnosis of tetrasomy 9p [8]. At birth, the phenotype of tetrasomy $9 p$ is usually immediately recognizable because of characteristic craniofacial appearance with hypertelorism/telecanthus, cleft palate/lip, ear malformation/malposition, bulbous/beaked nose, microgna- 
thia, large mouth with down-turned corners, epicanthal folds, brachycephaly/microcephaly/hydrocephaly, wide sutures/ large fontanels, short neck/excess nuchal skin, and microphthalmia/enophthalmia. Other major congenital anomalies are congenital heart disease, limb defects, vertebral/spinal abnormalities, central nervous system malformation, urogenital anomalies, renal anomalies, and gastrointestinal malformations.

The patient reported here had the typical phenotype of tetrasomy $9 p$ syndrome, including craniofacial findings, central nervous system malformation, congenital heart disease, and renal and gastrointestinal anomalies. In addition, the proband had a left hernia-type Bochdalek diaphragmatic defect.

$\mathrm{CDH}$ is a malformation with an estimated prevalence of $1 / 2000$ to $1 / 3000$ [6], with $84 \%$ being left-sided, $13 \%$ rightside, and $2 \%$ bilateral [3]. CDH may occur as an isolated malformation or in multiple malformation syndromes and associations. The exact frequency of $\mathrm{CDH}$ associated with multiple congenital anomaly syndromes or chromosomal abnormalities is unknown but dependent on case selection (prenatal vs autopsy cases). Several authors have shown that midline anomalies are commonly associated with $\mathrm{CDH}$ [10-12]. Several malformation syndromes, including Fryns syndrome, Beckwith-Wiedemann syndrome, SimpsonGolab-Behmel syndrome, Donnai syndrome, and Perlmann syndrome, associated with $\mathrm{CDH}$ also have midline defects as components of their phenotype [3].

Translocations involving the short arm of chromosome 9 were reported by several authors $[6,7,13]$ in patients with $\mathrm{CDH}$. In our case, the patient had $\mathrm{CDH}$ associated with a tetrasomy $9 \mathrm{p}$. These data suggest that genes present on the short arm of chromosome 9 may have a role in the etiology of $\mathrm{CDH}$ in this particular child. In fact, there are increasing experimental data suggesting that enzymes such as RALDH, involved in retinoids metabolism, as well as retinoid acid receptors (RAR and RXR) [14-18] might be essential for lung and diaphragm development as revealed by rodent animal model of $\mathrm{CDH}$. Interestingly, genes that synthesize for RALDH1 [19], RXR $\alpha$ [20], and RAR-related orphan receptor B [21] are localized on chromosome 9 at locus $9 \mathrm{q} 21.13$, 9q34.3, and $9 \mathrm{q} 22$, respectively. Regarding the background of the retinoid hypothesis in $\mathrm{CDH}$, chromosome 9 should be considered as potentially important.

The cause of $\mathrm{CDH}$ remains largely unknown, and no single gene mutation can be held responsible until now for this major congenital anomaly, whereas the genetic background of familiar occurrence is variable. Clinical evaluation of associated anomalies, together with increasing awareness of the genes involved in lung and diaphragm development, especially those guiding mesenchymal growth, may lead to our understanding of this anomaly.

\section{References}

[1] Ghymers D, Hermann B, Disteche C, et al. Partial tetrasomy of number 9 chromosome, and mosaicism in a child with multiple malformations. Humangenetik 1973;20:273-82.

[2] Tonk VS. Moving towards a syndrome: a review of 20 cases and a new case of non-mosaic tetrasomy $9 p$ with long-term survival. Clin Genet 1997;52:23-9.

[3] Enns GM, Cox VA, Goldstein RB, et al. Congenital diaphragmatic defects and associated syndromes, malformations, and chromosome anomalies: a retrospective study of 60 patients and literature review. Am J Med Genet 1998;79:215-25.

[4] Lurie IW. Where to look for the genes related to diaphragmatic hernia? Genet Couns 2003;14:75-93.

[5] Biggio Jr JR, Descartes MD, Carroll AJ, et al. Congenital diaphragmatic hernia: is 15q26.1-26.2 a candidate locus? Am J Med Genet 2004;126A:183-5.

[6] Torfs CP, Curry CJ, Bateson TF, et al. A population-based study of congenital diaphragmatic hernia. Teratology 1992;46:555-65.

[7] Donnenfeld AE, Campbell TJ, Byers J, et al. Tissue-specific mosaicism among fetuses with prenatally diagnosed diaphragmatic hernia. Am J Obstet Gynecol 1993;169:1017-21.

[8] Dutly F, Balmer D, Baumer A, et al. Isochromosomes 12p and 9p: parental origin and possible mechanisms of formation. Eur J Hum Genet 1998;6:140-4.

[9] Dhandha S, Hogge WA, Surti U, et al. Three cases of tetrasomy 9p. Am J Med Genet 2002;113:375-80.

[10] Cantrell JR, Haller JA, Ravitch MM. A syndrome of congenital defects involving the abdominal wall, sternum, diaphragm, pericardium, and heart. Surg Gynecol Obstet 1958;107:602-14.

[11] Opitz JM, Gilbert EF. CNS anomalies and the midline as a "developmental field". Am J Med Genet 1982;12:443-55.

[12] Khoury MJ, Cordero JF, Mulinare J, et al. Selected midline defect associations: a population study. Pediatrics 1989;84:266-72.

[13] Tibboel D, Gaag AV. Etiologic and genetic factors in congenital diaphragmatic hernia. Clin Perinatol 1996;23:689-99.

[14] Mendelsohn C, Lohnes D, Decimo D, et al. Function of the retinoic acid receptors (RARs) during development (II). Multiple abnormalities at various stages of organogenesis in RAR double mutants. Development 1994;120:2749-71.

[15] Thebaud B, Tibboel D, Rambaud C, et al. Vitamin A decreases the incidence and severity of nitrofen-induced congenital diaphragmatic hernia in rats. Am J Physiol 1999;277:L423 - 9.

[16] Greer JJ, Babiuk RP, Thebaud B. Etiology of congenital diaphragmatic hernia: the retinoid hypothesis. Pediatr Res 1973; 53:726-730.

[17] Babiuk RP, Thebaud B, Greer JJ. Reductions in the incidence of nitrofen-induced diaphragmatic hernia by vitamin $\mathrm{A}$ and retinoic acid. Am J Physiol Lung Cell Mol Physiol 2004;286:L970 - 3.

[18] Baptista MJ, Melo-Rocha G, Pedrosa C, et al. Antenatal vitamin A administration attenuates lung hypoplasia by interfering with early instead late determinants of lung underdevelopment in CDH. J Pediatr Surg 2005;40:658-65.

[19] Hsu LC, Yoshida A, Mohandas T. Chromosomal assignment of the genes for human aldehyde dehydrogenase-1 and aldehyde dehydrogenase-2. Am J Hum Genet 1986;38:641 - 8 .

[20] Almasan A, Mangelsdorf DJ, Ong ES, et al. Chromosomal localization of the human retinoid X receptors. Genomics 1994;20: 397-403.

[21] Jetten AM, Ueda E. Retinoid-related orphan receptors (RORs): roles in cell survival, differentiation and disease. Cell Death Differ 2002; 9:1167-71 